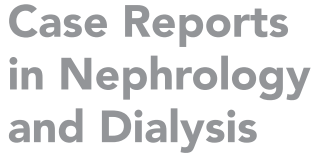

Case Reports and Dialysis

\title{
Nintedanib-Induced Renal Thrombotic Microangiopathy
}

\author{
Takeshi Fujita $^{a}$ Hideyuki Nakagawa ${ }^{c}$ Takashi Yokotab \\ Jun Umetani ${ }^{a} \quad$ Daiki Nagawa $^{a} \quad$ Masamichi Nakata $^{a}$ \\ Ikuyo Narita-Kinjo $^{a}$ Reiichi Murakami ${ }^{a}$ Michiko Shimada ${ }^{a}$ \\ Norio Nakamura ${ }^{a}$ Hirofumi Tomita ${ }^{a}$ b \\ aNephrology, Hirosaki University Graduate School of Medicine, Hirosaki, Aomori, Japan; \\ ${ }^{b}$ Cardiology, Hirosaki University Graduate School of Medicine, Hirosaki, Aomori, Japan; \\ 'Respiratory Medicine, Hirosaki National Hospital, Hirosaki, Aomori, Japan
}

\section{Keywords}

Drug-induced kidney injury · Idiopathic pulmonary fibrosis · Nephrotic syndrome · Nintedanib · Proteinuria · Thrombotic microangiopathy $\cdot$ Tyrosine kinase inhibitor

\begin{abstract}
Nintedanib is a unique tyrosine kinase inhibitor used to suppress fibrosis in patients with idiopathic pulmonary fibrosis (IPF). Nintedanib has been shown to suppress multiple processes of fibrosis, thereby reducing the rate of lung function decline in patients with IPF. Since vascular endothelial growth factor is one of this agent's targets, nephrotoxicity, including renal thrombotic microangiopathy (TMA), is a possible major adverse effect. However, only 2 previous cases of nintedanib-induced renal TMA have been published. Our patient was an 83-year-old man with IPF. As adverse effects including liver enzyme level elevation, diarrhoea, anorexia, and nephrotoxicity developed, the nintedanib dosage was reduced after 9 months. The digestive symptoms resolved promptly, but the proteinuria and reduced kidney function remained. Although the kidney injury had improved to some extent, we performed a percutaneous renal biopsy. The biopsy revealed typical TMA findings such as microaneurysms filled with pale material, segmental double contours of glomerular basement membranes, and intracapillary foam cells. After discontinuation of nintedanib, the patient's nephrotoxicity improved. Nintedanib-induced renal TMA is reversible and is possibly dose-dependent. Here, we report the clinical course of our case and review the characteristics of nintedanib-induced renal TMA.
\end{abstract}




\section{Introduction}

Various tyrosine kinase inhibitors (TKIs) have been developed for use in cancer patients. Their targets include vascular endothelial growth factor (VEGF), platelet-derived growth factor, fibroblast growth factor, and c-kit. Inhibition of VEGF signalling, the main process of angiogenesis, by the VEGF monoclonal antibody bevacizumab and VEGF receptor (VEGFR) inhibitors such as ranibizumab, ramucirumab, and aflibercept, cause a variety of nephrotoxicities, including hypertension, proteinuria, nephrotic syndrome, and renal thrombotic microangiopathy (TMA) [1-6]. Additionally, reports have suggested that TKIs, including VEGFR inhibitors, cause a variety of adverse effects on the kidney [6-8].

Idiopathic pulmonary fibrosis (IPF) is an interstitial lung disease characterised by the progressive loss of pulmonary function and the resultant degradation of quality of life. Nintedanib inhibits VEGFR, platelet-derived growth factor receptors, and fibroblast growth factor receptors and has been approved for the treatment of IPF since 2014 [9]. Nintedanib was initially developed for treating cancer, but the attenuation of fibrosis in a rat model of bleomycin-induced lung fibrosis has altered its indications [10]. This agent has shown efficacy in reducing the rate of lung function decline in patients with IPF by suppressing multiple processes of fibrosis.

Only 2 previous cases of nintedanib-induced renal TMA have been reported [11,12]. Here, we report the clinical course of our case and review the characteristics of nintedanib-induced renal TMA.

\section{Case Report}

An 83-year-old Japanese man with proteinuria, hypoalbuminemia, and kidney dysfunction was referred to our hospital. The detailed laboratory data upon presentation are shown in Table 1. Approximately 1 year and 3 months before the current evaluation, he had experienced dry cough and was diagnosed with IPF. One year and 2 months before, nintedanib $150 \mathrm{mg}$ twice daily had been initiated, and a urine test strip showed urinary protein $( \pm)$. Although mild liver enzyme elevation occurred 4 days after nintedanib treatment was initiated, it returned to the normal range within a few days of treatment with ursodeoxycholic acid. Diarrhoea and anorexia occurred 3 months later and continued for 6 months, although the patient's signs and symptoms of IPF had improved. During this period, the serum albumin decreased gradually (shown in Fig. 1); however, the urinary protein was not evaluated. The patient's diarrhoea and anorexia recovered during the 10-day discontinuation of nintedanib, so nintedanib $100 \mathrm{mg}$ twice daily was then initiated. Since the hypoalbuminemia had gradually deteriorated, urinary protein was checked 1 month later, at which time the urine protein/creatinine $(\mathrm{Cr})$ ratio was $7.90 \mathrm{~g} / \mathrm{g} \mathrm{Cr}$ (normal range: $<0.15 \mathrm{~g} / \mathrm{g} \mathrm{Cr}$ ). However, subsequent ratios were approximately $2 \mathrm{~g} / \mathrm{g}$ Cr. Additional medications administered to the patient included doxazosin mesylate $2 \mathrm{mg}$ twice daily, nifedipine controlled-release $20 \mathrm{mg}$ twice daily, telmisartan $80 \mathrm{mg}$, bisoprolol $2.5 \mathrm{mg}$, furosemide $40 \mathrm{mg}$, and trichlormethiazide $1 \mathrm{mg}$.

We performed a percutaneous renal biopsy, and periodic acid-Schiff staining indicated evidence of renal TMA (shown in Fig. 2a): typical microaneurysms filled with pale material, segmental double contours of glomerular basement membranes, and intracapillary foam cells [13]. Direct immunofluorescence identified non-specific deposits of immunoglobulin (Ig) A, IgM, and C1q, and no deposit of IgG and C3. Electron microscopy revealed microaneurysmal dilatation of a capillary loop with marked widening of the subendothelial spaces (Fig. 2b). Because these findings strongly indicated nintedanib-induced TMA, we consulted a pulmonologist and elected to discontinue the treatment. Although the nephrotic syndrome recovered within 1 year, the renal dysfunction persisted (Fig. 1). His hypertension also deteriorated with nintedanib and subsequently improved without it.

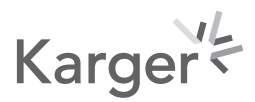


Case Reports in Nephrology and Dialysis

\begin{tabular}{l|l}
\hline Case Rep Nephrol Dial 2021:11:227-232 \\
\hline DOI: 10.1159/000517692 & $\begin{array}{l}\text { @ 2021 The Author(s). Published by S. Karger AG, Basel } \\
\text { www.karger.com/cnd }\end{array}$ \\
\hline
\end{tabular}

Table 1. Laboratory data on presentation

\begin{tabular}{|c|c|c|}
\hline Variable & On presentation to this hospital & Reference range \\
\hline White-cell count, per $\mathrm{mm}^{3}$ & 5,200 & $3,300-8,600$ \\
\hline Red blood cell count, per mm ${ }^{3}$ & $309 \times 106$ & $435-555 \times 106$ \\
\hline Haemoglobin, g/dL & 10.0 & $13.7-16.8$ \\
\hline MCV, fL & 96.4 & $83.6-98.2$ \\
\hline $\mathrm{MCHC}, \mathrm{g} / \mathrm{dL}$ & 33.6 & $31.7-35.3$ \\
\hline Platelet count, per mm ${ }^{3}$ & $18.2 \times 104$ & $15.8-34.8 \times 104$ \\
\hline Blood urea nitrogen, $\mathrm{mg} / \mathrm{dL}$ & 25 & $8-20$ \\
\hline $\mathrm{Cr}, \mathrm{mg} / \mathrm{dL}$ & 1.36 & $0.65-1.07$ \\
\hline EGFR, $\mathrm{mL} / \mathrm{min} / 1.73 \mathrm{~m}^{2}$ & 39.0 & $>60$ \\
\hline Total protein, g/dL & 8.8 & $6.6-8.1$ \\
\hline Albumin, $\mathrm{g} / \mathrm{dL}$ & 5.1 & $4.1-5.1$ \\
\hline Cystatin C, mg/L & 1.47 & $0.50-0.90$ \\
\hline Sodium, mmol/L & 142 & $138-145$ \\
\hline Potassium, mmol/L & 4.3 & $3.6-4.8$ \\
\hline AST, U/L & 31 & $13-30$ \\
\hline ALT, U/L & 21 & $10-42$ \\
\hline $\operatorname{HbA1c}(\%)$ & 5.4 & $4.9-6.0$ \\
\hline IgG, mg/dL & 525 & $861-1747$ \\
\hline $\operatorname{IgA}, \mathrm{mg} / \mathrm{dL}$ & 190 & $93-393$ \\
\hline IgM, mg/dL & 124 & $33-183$ \\
\hline $\mathrm{C} 3, \mathrm{mg} / \mathrm{dL}$ & 77 & $73-138$ \\
\hline $\mathrm{C} 4, \mathrm{mg} / \mathrm{dL}$ & 16 & $11-31$ \\
\hline Antinuclear antibody (fold) & 80 & \\
\hline ANCA (fluorescent antibody method) & Negative & Negative \\
\hline D-dimer, $\mu \mathrm{g} / \mathrm{mL}$ & 8.8 & $0.0-1.0$ \\
\hline Urine protein/Cr ratio, $\mathrm{g} / \mathrm{gCr}$ & 1.62 & $<0.15$ \\
\hline Urine red blood cell (/HPF) & $<1$ & $0-4$ \\
\hline Urine Cast & Negative & Negative \\
\hline Urine $\beta 2$ microglobulin, $\mu \mathrm{g} / \mathrm{L}$ & 150 & $0-300$ \\
\hline Urine NAG, U/L & 7 & $0-5$ \\
\hline
\end{tabular}

$\mathrm{MCV}$, mean corpuscular volume; MCHC, mean corpuscular haemoglobin concentration; eGFR, estimated glomerular filtration rate; AST, aspartate transaminase; ALT, alanine transaminase; HbA1c, haemoglobin A1c; IgG, immunoglobulin G; IgA, immunoglobulin A; IgM, immunoglobulin M; ANCA, antineutrophil cytoplasmic antibody; NAG, N-acetyl- $\beta$-D-glucosaminidase; $\mathrm{Cr}$, creatinine.

\section{Discussion}

This case indicates that nintedanib-induced TMA might be reversible and dose-dependent. Hence, regular urine tests are important to check the urinary protein.

In this case, nintedanib induced hypertension, proteinuria, nephrotic syndrome, and eventually renal TMA. In many reports of the other TKIs, the drug discontinuation criterion was proteinuria $\geq$ grade 2 ( $2+$ or $3+$ on urine test strips; $1.0-3.5 \mathrm{~g} /$ day $)$. We discontinued the 


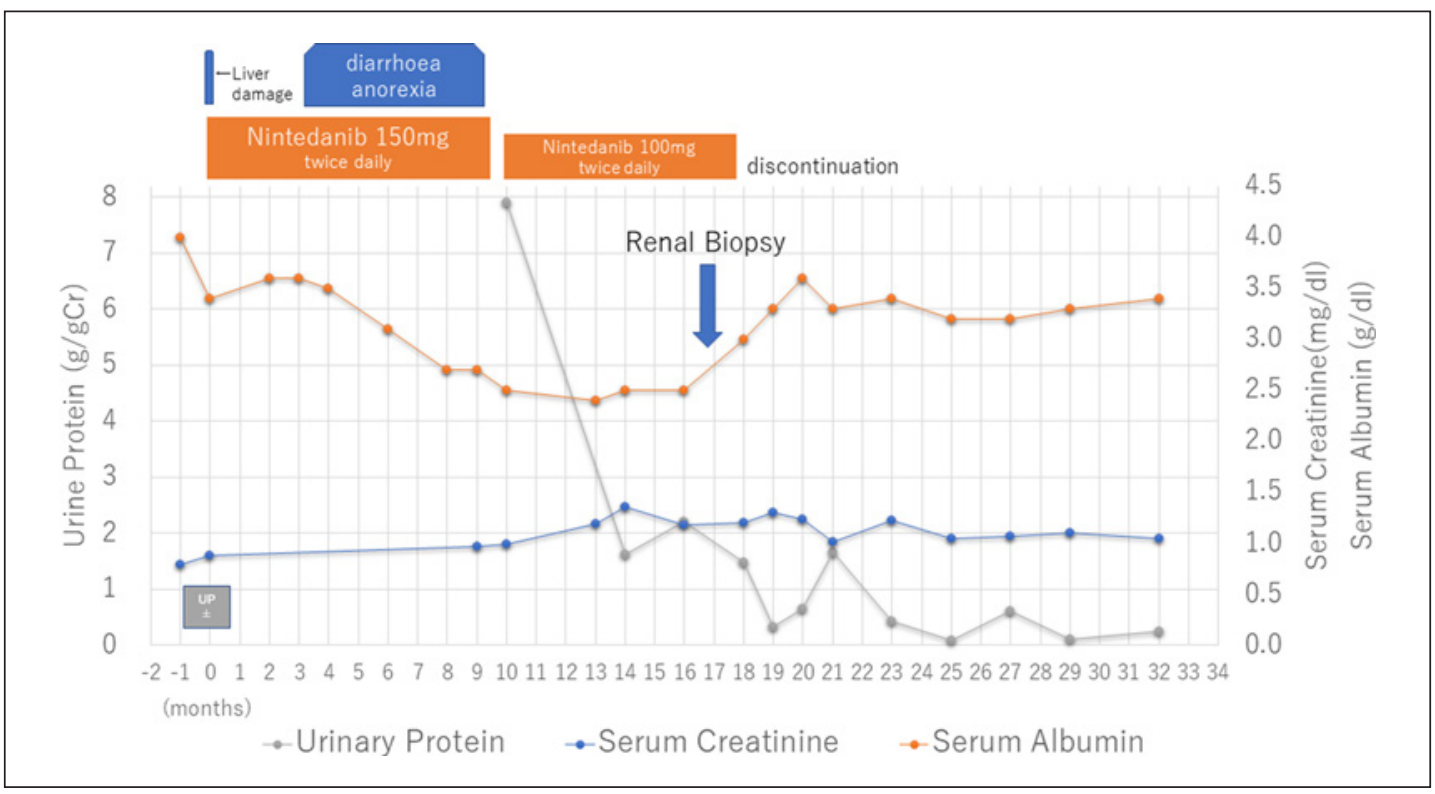

Fig. 1. Clinical course of the present case regarding urine protein, serum $\mathrm{Cr}$, and serum albumin levels. Cr, creatinine.
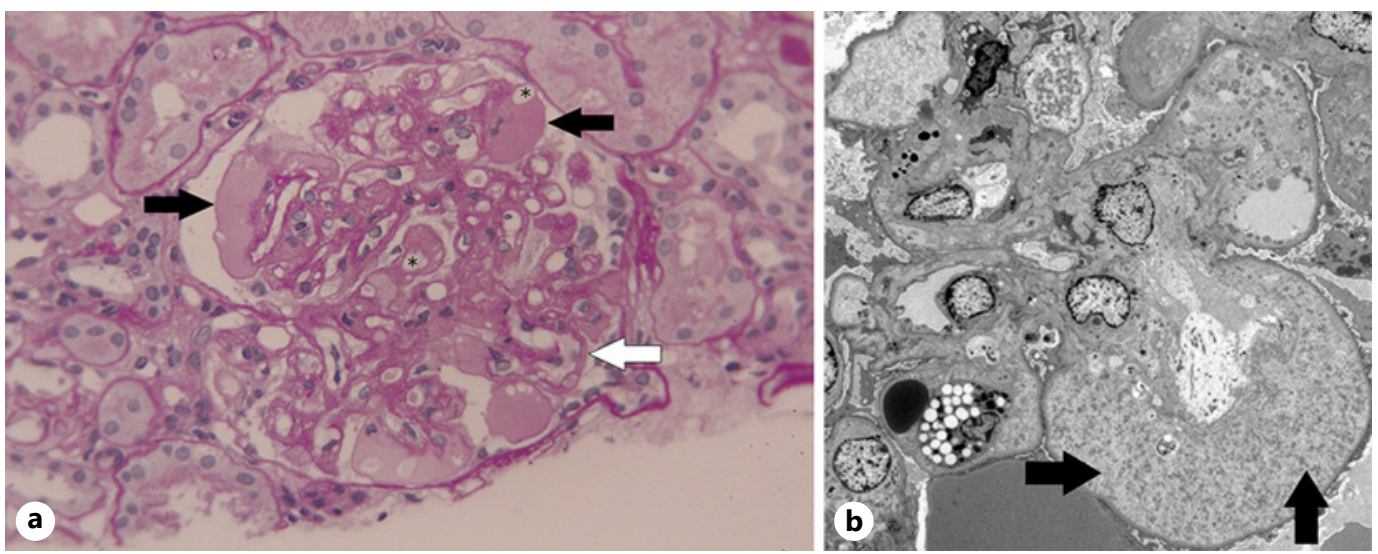

Fig. 2. The pathological features of nintedanib-induced glomerular thrombotic angiopathy. a Light microscopy with periodic acid-Schiff staining shows typical microaneurysms filled with pale material (black arrows), segmental double contours of glomerular basement membranes (white arrow), and intracapillary foam cells (asterisks) (original magnification $\times 400$ ). b Electron microscopy shows microaneurysmal dilatation of a capillary loop with marked widening of the subendothelial spaces (arrows) (original magnification $\times 1,500)$.

agent because of the evidence of nephrotic syndrome and renal TMA in the patient. The patients in both previous published cases of nintedanib-induced TMA recovered with discontinuation of the drug $[11,12]$, and however, the discontinuation of nintedanib must be carefully discussed with a pulmonologist.

Although diarrhoea and anorexia continued during the course of nintedanib $150 \mathrm{mg}$ twice daily, such digestive symptoms improved after reduction to $100 \mathrm{mg}$ twice daily. The hypoalbuminemia also improved with this reduction. This course indicates that the adverse effects of nintedanib are potentially dose-dependent. Therefore, the agent could have been 
Case Reports in Nephrology and Dialysis

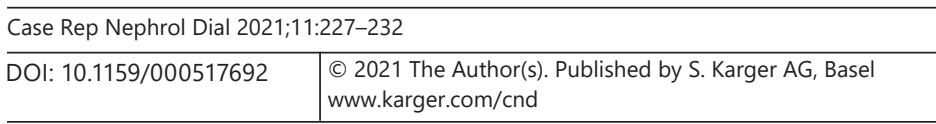

Fujita et al.: Nintedanib-Induced Renal TMA

continued in this case, as it appeared that all adverse effects, including proteinuria, had improved (Fig. 1). Regular urine tests should be performed for patients receiving TKIs, as this examination is non-invasive and useful for the early diagnosis of renal TMA and other conditions.

The predictive factors for the development of proteinuria in patients receiving anti-VEGF therapy were identified as high systemic blood pressure, calcium channel blocker administration, and a higher number of therapy cycles [14]. Our patient had used a calcium channel blocker, but his systolic blood pressure remained high. Although this is a case report, these findings are useful for future cases.

\section{Statement of Ethics}

Written informed consent was obtained from the patient for publication of this case report and any accompanying images. Independent Ethics Committee of Hirosaki University School of Medicine and Hospital has been approved for publication. The date of approval was January 24th, 2021.

\section{Conflict of Interest Statement}

The authors have no conflicts of interest to declare.

\section{Funding Sources}

The authors did not receive any funding.

\section{Author Contributions}

Takeshi Fujita: conceptualization, writing-original draft. Hideyuki Nakagawa: investigation. Takashi Yokota: investigation. Jun Umetani: investigation. Daiki Nagawa: investigation. Masamichi Nakata: investigation. Ikuyo Narita: investigation. Reiichi Murakami: supervision. Michiko Shimada: supervision. Norio Nakamura: supervision. Hirofumi Tomita: supervision.

\section{References}

1 Zhu X, Wu S, Dahut WL, Parikh CR. Risks of proteinuria and hypertension with bevacizumab, an antibody against vascular endothelial growth factor: systematic review and meta-analysis. Am J Kidney Dis. 2007 Feb; 49(2):186-93.

2 Eremina V, Jefferson JA, Kowalewska J, Hochster H, Haas M, Weisstuch J, et al. VEGF Inhibition and renal thrombotic microangiopathy. N Engl J Med. 2008;358(11):1129-36.

3 Ranpura V, Pulipati B, Chu D, Zhu X, Wu S. Increased risk of high-grade hypertension with bevacizumab in cancer patients: a meta-analysis. Am J Hypertens. 2010 May;23(5):460-8.

4 Cheungpasitporn W, Chebib FT, Cornell LD, Brodin ML, Nasr SH, Schinstock CA, et al. Intravitreal antivascular endothelial growth factor therapy may induce proteinuria and antibody mediated injury in renal allografts. Transplantation. 2015 Nov;99(11):2382-6.

5 Piscitani L, Sirolli V, Di Liberato L, Morroni M, Bonomini M. Nephrotoxicity associated with novel anticancer agents (aflibercept, dasatinib, nivolumab): case series and nephrological considerations. Int J Mol Sci. 2020 Jul $10 ; 21(14): 4878$. 
6 Estrada CC, Maldonado A, Mallipattu SK. Therapeutic inhibition of VEGF signaling and associated nephrotoxicities. J Am Soc Nephrol. 2019 Feb;30(2):187-200.

7 Semeniuk-Wojtas A, Lubas A, Stec R, Szczylik C, Niemczyk S. Influence of tyrosine kinase inhibitors on hypertension and nephrotoxicity in metastatic renal cell cancer patients. Int J Mol Sci. 2016 Dec 9;17(12):2073.

8 Zhang Z-F, Wang T, Liu L-H, Guo H-Q. Risks of proteinuria associated with vascular endothelial growth factor receptor tyrosine kinase inhibitors in cancer patients: a systematic review and meta-analysis. PLoS One. 2014 Mar;9(3): e90135.

9 Richeldi L, du Bois RM, Raghu G, Azuma A, Brown KK, Costabel U, et al. Efficacy and safety of nintedanib in idiopathic pulmonary fibrosis. N Engl J Med. 2014 May;370(22):2071-82.

10 Chaudhary NI, Roth GJ, Hilberg F, Müller-Quernheim J, Prasse A, Zissel G, et al. Inhibition of PDGF, VEGF and FGF signalling attenuates fibrosis. Eur Respir J. 2007 May;29(5):976-85.

11 Hasegawa M, Uehara A, Suzuki T, Sekine R, Yazawa M, Ichikawa D, et al. Nintedanib-induced glomerular microangiopathy: a case report. CEN Case Rep. 2020 Nov; 9(4):295-300.

12 Inoue D, Nishi H, Honda K, Ishii T, Abe H, Sato M, et al. Renal thrombotic microangiopathy during nintedanib treatment for idiopathic pulmonary fibrosis. Clin Nephrol. 2020 Jan;93(1):47-50.

13 Pfister F, Amann K, Daniel C, Klewer M, Büttner A, Büttner-Herold M. Characteristic morphological changes in anti-VEGF therapy-induced glomerular microangiopathy. Histopathology. 2018 Dec;73(6):990-1001.

14 Kanbayashi Y, Ishikawa T, Tabuchi Y, Sakaguchi K, Ouchi Y, Otsuji E, et al. Predictive factors for the development of proteinuria in cancer patients treated with bevacizumab, ramucirumab, and aflibercept: a singleinstitution retrospective analysis. Sci Rep. 2020 Feb;10(1):2011. 